8) Linkage with the Islam Centennial Fourteen Committee, which shares the goals of furthering understanding through the use of various media, including films, art and museum exhibits, and community events.

\title{
NEWS OF OTHER ASSOCIATIONS AND NEV JOURNALS
}

Editorial Note: The reports of AMIDEAST, APPME and the Society for Coptic Archaeology at Cairo, as received, were significantly fuller. Due to new and stringent restrictions on space, these unfortunately had to be much reduced in length. Any errors or misleading statements they may contain are, therefore, the editor's responsibility.

America-Mideast Educational \& Training Services (AMIDEAST)

Founded in 1951 as American Friends of the Middle East (AFME), AMIDEAST has contributed nearly 30 years of non-profit service to educational and cultural exchanges and increased mutual understanding between the U.S. and the countries of the Islamic Middle East and North Africa. Over the past 20 years AMIDEAST has focused primarily on facilitating the most beneficial and economical use of American post-secondary level education and expertise by Middle Eastern and North African individuals and institutions, for personal and national development purposes. More recently, its Board of Directors and over 80 staff members have designated in-regional education for development as a priority for the 1980 s.

Educational Services: AMIDEAST's Washington, D.C. headquarters and its network of eight field offices provide counseling, placement orientation and supervision services to Middle Eastern students interested or engaged in U.S. study programs. It also offers consultation and information services to Middle Eastern and North African government ministries, private corporations and educational institutions. AMIDEAST has also assisted various Ministries of Education in implementing their U.S.-based student scholarship programs, as well as supervising scholarships offered by corporations, philanthropic individuals, and USAID graduate scholarships available to Egypt. Field offices offer a number of free counseling and information services to students wishing to ascertain if U.S. study is a viable option for them. A special service of AMIDEAST, since the early ' $60 \mathrm{~s}$, has been its annual Scholarship Search on behalf of outstanding but needy students, at no cost to the applicant. Regrettably, this service has been temporarily discontinued until funding can be obtained.

Programming and Facilitative Services: In addition to formal higher education program counseling and administration, AMIDEAST has arranged short-term professional study tours of the U.S. for Middle Eastern individuals and groups, and for U.S. visitors to the Middle East and North Africa.

AMIDEAST field offices have also facilitated the work of other cultural and educational exchange groups in the Middle East and North Africa by assisting in the interviewing, selection and orientation of participants in Experiment in International Living, American Field Service, Bi-National Commissions, and university exchange programs. A unique program of language teacher exchanges, commended by President Carter, has been supported by the Tunis office, in which Tunisian French teachers are exchanged with American schools in Louisiana and other traditionally French-speaking areas.

Information Services: In support of its educational services, and of cultural exchange generally, AMIDEAST headquarters and field of- 